\title{
Yenilikçi Örgüt İklimi: İșe Adanma Üzerine Etkisi
}

\section{Elif Baykal*}

\section{Özet}

Inovasyon, işletmelerin yeni fikir ve ürünler geliştirerek piyasada yeni yerler edinmeleri ya da olan pozisyonlarını daha da güçlendirmeleridir. Örgütlerin daha yenilikçi yani inovatif davranabilmeleri için örgüt kültürlerinin de yeniliğe açık ve teşvik eder yapıda olması çok önemlidir. Bu çalışmada yenilikçi örgüt ikliminin çalışanların işe adanmaları üzerinde olumlu etkisi olacağl öngörülmüş ve bu ilişkiyi test etmek için Türkiye'de faaliyet gösteren kurumsal şirketlerde görev yapan beyaz yakalı çalışanlar üzerinde bir saha araştırması düzenlenmiştir. İlgili saha araştırmasında 203 kullanılabilir anket elde edilmiştir. Araştırmaya Araştırma sonuçları SPSS 20. ile analiz edilmiştir. Çalışmada öncelikle yenilikçi örgüt iklimi ve işe adanma kavramları üzerinde durulmuş daha sonra da bu iki kavram arasındaki ilişkiyi inceleyen saha araştırmasına ait sonuçların analizlerine yer verilmiştir. Analiz sonuçlarına göre hipotezlerde varsayıldiğı gibi yenilikçi örgüt iklimi çalışanların işe adanma eğilimleri üzerinde pozitif etkiye sahip olduğu görülmüş̧ürr.

Anahtar kelimeler: İnovasyon, Yenilikçilik, Yenilikçi örgüt iklimi, İşe adanma

JEL Sinıflandırması: M12, O31

\section{Innovative Work Climate: Effects on Work Engagement}

\begin{abstract}
Innovation is the ability of contemporary organizations to develop new ideas and products, to gain new positions in the market or to strengthen their existing positions. In order for organizations to behave more innovative, it is very important that organizational cultures are open to innovation and encouraging. In this study, the innovative organizational climate is predicted to have a positive impact work engagement of employees. To test this relationship, a field research on white-collar employees who work in corporate companies operating in Turkey was arranged.203 usable questionnaires were obtained in the relevant field research. The results of the research were analyzed with SPSS 20. In this study, firstly the concepts of innovative organizational climate and devotion to work are discussed, and then the results of the field research examining the relationship between these two concepts are given. According to the results of the analysis, the hypothesis hypotheses that the innovative organizational climate has a positive effect on employees' work engagement.
\end{abstract}

Keywords: Innovation, Innovativeness, Innovative work climate, Work engagement

JEL Classification: $M 12,031$

\footnotetext{
* Dr.Öğr.Üyesi, İstanbul Medipol Üniversitesi, İşletme ve Yönetim Bilimler Fakültesi, Havacıllk Yönetimi Bölümü enarcikara@medipol.edu.tr
} 


\section{Giriş}

İnovasyon yani yenilik, yeni ve faydalı yaratıcı fikirlerin başarılı bir şekilde uygulanmasıdır (Amabile, 2004). Örgütsel anlamda bakıldığında, inovasyon yani yenilik örgütlerin daha önce yapılmamış bir yenilikle faydalı ve meydan okuyucu bir üretimde bulunmaları olarak kabul edilebilir. Örgütsel yenilik, herhangi bir yeni ürünün, sürecin veya sistemin bir kuruma tanıtılması anlamına gelir (Sarros, Cooper and Santora, 2008: 146). Janssen (2000), inovasyonun, çalışanların çalışma ortamlarını değiştirerek sorunlarla başa çıkabildiği problem odaklı bir baş etme biçimi olarak sınıflandırılabileceğin savunur (Janssen, 2000). Yenilikçi örgüt iklimi, çalışanların yeni fikirlerin üretilmesini teşvik eden uygulamalar, prosedürler ve davranışlar, yaratıcı düşüncelerle denemeler ve değişikliklerin kabulü hakkındaki paylaşılan algılarını yansıtır (Cai vd. 2017:4). Chen vd.'e (2010) göre yenilikçi örgüt iklimi, çalışanların bilgi alışverişinde bulunmalarını teşvik eden başlıca çevresel faktördür.

Çalışanların inovatif yani yenilikçi davranışlar gösterebilmeleri, örgütsel inovasyon/yenilik, rekabet avantajı ve sürdürülebilirlik için en önemli faktörlerden biri olarak yaygın şekilde kabul edilmiştir (George \& Zhou, 2001). İnovasyon performansı için örgütlerin gerekli gördüğü iklime yenilikçi örgüt iklimi denir (Popa vd, 2017:3). Menzel vd. (2007) de çalışanların inovasyon kapasitesini, yaratıcılık, risk eğilimi ve kişisel büyümeyi teşvik eden örgütsel iklimleri yenilikçi kültürler olarak adlandırmışlardır. Yenilikçi örgüt iklimi, örgüt içerisinde inovasyona yönelik doğrudan davranışsal önlemler almak zor olmadığında yararlı bir araçtır (Sarros, Cooper and Santora, 2008: 146). Yenilikçi örgüt iklimi, örgütsel sistemlerin anlamlı bir bağlamsal unsuru olarak tanımlanmıştır (King, Chermont, West, Dawson ve Hebl, 2007). Örgütsel yenilik/inovasyon, organizasyon içinde mevcut olan kolektif bireysel yenilikçiliğin/inovatifliğin varlığından kaynaklanmaktadır (Gosh, 2015). Yenilikçi örgüt iklimi, çalışanlarla yakinen ilgilenmeyi, keyifli bir iş ortamını, örgüt içi açık iletişimi, örgüt içerisindeki yöneticilerin çalışanlarına sağladığı duygusal ve işlevsel desteği, çalışanların yaratıcılıklarını kullanma istekliliğini, fikir ve sorumluluk paylaşımı gibi sosyo-çevresel bağlam faktörlerini içerir (Gosh, 2019: 9).Kuşkusuz, örgütlerde yenilikçi iklim, örgüt kültürü, inovasyon süreçlerini kolaylaştıran, firma üyeleri tarafından paylaşılan değerler, inançlar ve varsayımlara dayanır (Popa vd., 2017:3). Örgütsel yenilik kültürü, örgütün vizyonu için bir mercektir ve organizasyonların yenilikçi olması için gerekli ortamın oluşturulmasına yardımcı olur (Sarros, Cooper ve Santora, 2008: 148).

\section{Yenilikçi Örgüt İklimi}

Bireysel düzeyde, iklim örgütsel bir durumun bilişsel yorumudur (Scott ve Bruce, 1994: 582). Psikolojik iklim teorisi savunucuları, bireylerin öncelikli olarak çevreye değil çevrenin bilişsel temsillerine cevap verdiklerini ifade etmişlerdir. İnovasyon için yenilikçi örgüt iklimi, bir kuruluşun değer ve normlarının inovasyonu ne ölçüde vurguladığ şeklinde tanımlanabilir. İnovasyonu destekleyen iç ortama "yenilikçi örgüt iklimi” denir ve rekabet avantajı oluşturmak ve performansı artırmak için inovasyondan/yenilikçilikten yararlanan kuruluşlar için çok önemlidir (Shanker et al., 2017:3). İklim, bireylerin gösterdikleri davranışların şekillendirilmesinde, örgütsel beklentiler ve davranışların oluşturduğu sinyalleri ifade eder. İklim bireysel davranışın belirleyicisi olarak kavramsallaştırıldığında ve iklimin kurumsal ve bölgesel inovasyon üzerindeki etkisine yönelik önceki ampirik destekler göz önüne alındığında, kuruluş üyelerinin inovasyonu desteklediği örgütsel iklimlerde inovatif davranışın olumlu etkilendiği görülür (Scott ve Bruce, 1994: 583). Bu anlamda, örgütsel inovasyon iklimi, ya da bir diğer deyişle yenilikçi örgüt iklimi yenilikçi davranış için önemli bir bağlamsal koşuldur. Scott ve Bruce'a (1994) göre bir kuruluşun inovasyon ortamı, kuruluşun risk alma davranışını teşvik eden, yenilikçilik için gerekli olan yeterli kaynakları tahsis eden ve iş ortamında yenilikçi bir yaklaşım kullanmak için zorlu bir çalışma ortamı sağlayan özelliklere karşı çalışanların algısıdır. Yine Scott ve Bruce'a (1994) göre yenilikçi örgüt iklimi çalışanların örgütlerinin risk alma meydan okuyucu teşebbüslerde bulunma eğilimleri ve kaynakların dağıtımı ile ilgili olarak ne denli örgütün genelinde kapsayıcı ve adil olduklarına dair 
algidir.

Yenilikçi örgütler, yaratıcılık ve yenilikçi değişime yönelik bir yönelim, üyelerine yeni fikirlerin peşinden bağımsız hareket etmeleri ve üyeler arasındaki çeşitliliğe tolerans göstermeleri ile karakterize edilir. Son olarak, ekipman, tesis ve zaman gibi kaynakların yeterli tedariki inovasyon için kritik öneme sahiptir ve bu tür kaynakların temini, inovasyon için örgütsel desteğin bir başka tezahürüdür (Scott ve Bruce, 1994: 583). Yenilikçi örgüt iklimi, ekip işbirliği, üstün destek, özerklik ve yeterli kaynaklar gibi unsurları içerir. Yenilikçi iklim ne kadar güçlüyse, çalışanların dahil olma ve kuruluşa bağlılık hissetme yoluyla yenilikçi olma olasılıkları o kadar yüksektir (Ren and Zhang, 2015: 18).

Hunter, Bedell ve Mumford'a (2007) göre örgütsel iklim çalışanların içsel motivasyonunu artırır ve böylece yaratıcılıkları üzerinde pozitif bir etki yaratır. Başka bir ifade ile, organizasyonlar bireyler tarafından pozitif olarak algılanan bir örgütsel iklim geliştirebildiklerinde, daha yüksek kurumsal performans, daha yüksek çalışan motivasyonu, örgütsel bağlilık ve özdeşleşme elde ederler (Shanker et al., 2017:6). İlgili alan yazını incelendiğinde destekleyici örgüt ikliminin birçok öncülü olduğu görülmüştür. Örneğin; Von Krogh vd.'un 2000 yılında yaptığ 1 çalışma, çalışma atmosferinin güven ve açık iletişim temelli olması, bilgi paylaşımını ve yaratıcı çıktılarını kolaylaştırdığını göstermiştir. Hammond, Neff, Farr, Schwall ve Zhao (2011) tarafından çalışanların yenilikçiliğinin öncülleri üzerinde yapılan bir meta-analizde ise, iş özelliklerinin ve özerkliğin, yaratıcılık veya yenilikçiliğe desteğin, pozitif örgüt ikliminin, organizasyonel yenilikçilik kaynaklarının varlığının ve denetleyici desteğin varlığ gibi bağlamsal faktörlerin hem fikir üretme hem de fikir uygulamalarıyla pozitif ilişkili olduğunu saptamıştır. Khan vd. (2016) de örgütte çalışanlara güvenli, sakin, etkileyici ve motivasyonel yenilikçi bir iklim sağladığında örgüt bireylerinin daha rahat inovatif iş davranışlarını benimsediğini savunmaktadır. İlgili alan yazınında, yenilikçi örgüt kültürü oluşumunun önemli öncüllerden birinin de bilgiyi edinme eğilimi olduğunun alt1 çizilmektedir. Aktif olarak yeni fikirler toplayan kuruluşlar, uygulamalarında pratik destek sağlar ve sonuçları hakkında geri bildirimde bulunurlar, müşterilerin ve müşterilerin değişen ihtiyaçları ve ihtiyaçları için daha verimli, üretken ve esnek olurlar (Eden ve King, 2017: 634).

Cerne vd. (2013), destekleyici bir yenilik ortamının, destekleyici ve güvenli bir iklimi teşvik etmenin çalışanların yaratıcılığını teşvik ettiğini tespit etmişlerdir. Shalley vd. (2004) çalışan yaratıcılığının bireysel faktörlere ve çalıştıkları bağlamlara bağlı olduğunu savunmuştur. Yaratıcı fikirlerin veya işlemlerin üretilmesini ve uygulanmasını destekleyen bir iklimin korunması, kurumların performansı ile ilgilidir. Genel olarak bakıldığında, yenilikçi örgüt ikliminin daha inovatif örgütlerin inşasını desteklediğini ampirik olarak destekleyen bir çok ampirik çalışma mevcuttur (Chandler vd., 2000; Dulaimi vd., 2005).

Yenilikçi örgüt iklimi, çalışanların iş taleplerinin olumsuz sonuçlarına karşı koyan yeni bireysel başa çıkma mekanizmaları geliştirmelerini ya da işle ilgili süreçleri geliştirmelerini sağlayabilir (Eden ve King, 2017: 634). Yenilikçi örgüt iklimine sahip şirketlerde, çalışanların ve yöneticilerin inovasyonun olası başarısızlığı konusundaki endişelerini hafifletir (Cai vd., 2017:6). Başarısızlık korkusu çalışanların inovatif hamleler yapmasını engellemez. Örgüt üyeleri risk almaya odaklıdır. Genellikle inovatif örgütler, otonomiye büyük önem verirler, örgüt üyelerinin rahatlıkla risk alabilecekleri, risk konusunda toleranslı örgütlerdir (Martins veTerblanche, 2003; Steele ve Murray, 2004). Yeni fikirlerin geliştirilmesi ve uygulanması, işgücünün işlerinin zorlu şartlarıyla başa çıkmalarını sağlayabilir. Yenilikçi bir örgüt ikliminde çalışan bireyler, görevleri gerçekleştirmek için yeni, sofistike ve riskli araçları aramaya ve deneyimlemeye eğilimlidirler (Cai vd. 2017: 4). Destekleyici bir örgütsel iklim, çalışanların potansiyellerini özgürce kullanmalarına yol açtığı için örgüt politikalarının önemli bir yönü olarak kabul edilmektedir (Waheed vd., 2019: 5). Daha önceki çalışmalar, destekleyici bir örgütsel iklimin, çalışanlar tarafından tetiklenen yenilikleri benimseme ve teşvik etme eğilimi gösterdiğini tespit etmiştir. Örgütlerin, çalışanların zorlukları algılamayı teşvik etmesi, risk faktörü için rekabet edebilecek yeterli teknolojiyi sağlaması ve yenilikçi çalışma 
yaklaşımının kullanımı için zorlu çalışmalar yapması için bir çalışma ortamı yaratmaktadır (Waheed vd., 2019: 5). Yenilikçi örgüt iklimi çalışanlara zorlayıcı ve meydan okuyucu hedefler koyarak organizasyonu kendi potansiyelini aşma konusunda olumlu yönde etki eder. Örgütsel bir nitelik olarak yenilikçi örgüt iklimi, gelişim veya iyileştirme çabaları için verimli bir alt yapı olarak kabul edilir (Isaksen ve Ekvall, 2010). Bireylerin örgüt içerisinde kendi bilgi ve becerilerini kullanabilecekleri fırsatların verilmesi ve bu becerilerin kullanımının örgüt tarafından teşvik edilmesi çalışanların inovatif davranışlar benimsemesinde ana etkenlerden biridir ve daha da önemlisi çalışanların iş ortamında motive olmalarını sağlar. Bu motivasyonla çalışan bireyler örgütün rekabet avantajı sağlamasında ve oldukça talepkar olan rekbaetçi piyasalara tutunmasında önemli bir kaynak olarak karşımıza çıkmaktadır (Khan vd., 2016: 54). Dolayısıyla, yenilikçi örgüt iklimleri organizasyonların performansını, çalışma yaşam kalitesini ve dolayısıyla işyerinde mutluluğu eşzamanlı olarak iyileştirmeyi kolaylaştırır (Pot, 2017:95).

Aslında, örgütsel yenilik iklimi organizasyon içerisinde motivasyon ve davranışın belirleyicisi olarak kabul edilebilecek psikososyal bir süreçtir. Örgütlerin inovasyonunu desteklemesi için çalışanlarına psikososyal destek sağlamanın ötesine geçmesi gerekir. Yenilikçi bir örgüt iklimi yaratan ve koruyan kuruluşlar, zorlu çalışmaların olumsuz sonuçlarının bir kısmını hafifletebilir (Eden ve King, 2017: 635). Değişim girişimlerini destekleyen veya teşvik eden kuruluşlar

Yenilikçilik araştırmaları, yenilikçilik ortamını etkileyen birkaç örgütsel boyut olduğunu göstermiştir. Araştırmacılar, ödüllendirmenin ve yaratıcılığın tanınmasında, yaratıcılığa yönelik çalışma ortamını kolaylaştırmanın önemli rol oynadıklarını belirlemiştir (Berman ve Kim, 2010). Ayrıca, yöneticilerin astlarla etkili iletişimi ve adil performans değerlendirmeleri, yönetici odaklı bir örgüt kültürü ile pozitif olarak ilişkilendirilmektedir. Örgütlerde, yönetimin inovatif bir ortam yaratmaya yönelik strateji geliştirme kapasitesi, değişim için yüksek düzeyde esneklik sağlanması, yenilikçi çözümler üretmek için gerekli kaynakların sağlanmasını ve çalışanların yaratıcılık konusundaki eğilimlerinin farkında olmayı gerektirir (Kim ve Yoon, 2015:161). Bunun yanında, inovasyon konusundaki araştırmacılar, çalışanların daha inovatif örgüt üyeleri haline gelmesi için yüksek seviyede yenilikçiliği destekleyen bir organizasyon inovasyon ortamının ve düşük zaman baskısının en uygun durum olduğunu iddia etmektedir. Uygulayıcılar yenilikçi örgüt ortamının istenen seviyede yenilikçi olmadığı ve zaman baskısının yüksek olduğu yaratıcılığın azaldığını göstermektedir (Hsu ve Fan, 2010: 379).

\section{3. İşe Adanma}

Schaufeli ve Bakker (2004) işe adanmışlı̆̆ olarak tanımlanmaktadır. Maslach, Schaufeli ve Leiter'in (2001) analizine göre, işe adanma, örgütsel bağlılık, iş tatmini veya işe katılım gibi yapılardan farklıdır. Örgütsel bağlılık, bir çalışanın istihdam sağlayan kuruluşla olan ilişkisine atıfta bulunurken, özellikle organizasyona odaklanır, işe katılım işin kendisine odaklanır). İ tatmini ise, işin bir gereksinimi yerine getirme ve memnuniyet kaynağı ya da çalışanları güçlüklerden ya da memnuniyetsizlikten kurtarmanın bir yoludur; kişinin, ürünün kendisiyle olan ilişkisini kapsamaz. İşe katılım (job involvement) ise, işe katılımın yönüyle işe adanmaya benzer, ancak enerji ve etkinlik boyutlarını içermez.

Schaufeli vd. (2001) işe adanmayı canlılık, adanma ve özümseme olarak üç boyutta ele alır. Bu boyutlardan canlılık; çalışırken yüksek enerji ve zihinsel esneklik ile karakterizedir. Canlılık, çalışanların iş yaparken gösterdikleri isteklilik, zihinsel dayanıklılık ve çeviklik olarak tanımlanmaktadır. Ayrıca, canlılık, kişinin işine odaklanmasına kolay sıkılıp bunalmamasına ve zorluklar karşısında daha dayanıklı olmasına denir. Adanma, birinin çalışmasına şiddetle dahil olmak ve iş ortamında anlam, coşku ve meydan okuma duygusu yaşamak anlamına gelir. Kişinin işine önem vermesi, işinden gurur duyması, hevesle çalışması işinden ilham almasıdır. Özümseme ise, bir kişinin işine tamamen konsantre ve mutlu bir şekilde dahil edilmiş olması ile karakterize edilir, böylece zaman hızlı bir şekilde geçer ve bir kişi işten ayrılmakta zorluk çeker (ayrıca bkz. 
Schaufeli ve Bakker, 2004). Özümseme (emilim) işe adanmaktan çok mutlu olmak, işe bağlanmak ve işten asla ayrılmak istememek. Çalışırken işe kapılıp gitmek ve zamanın nasıl geçtiğini anlamamaktır (Schaufeli et al. 2002). Utrecht "İşe Adanmışlık Ölçeği”"nde yüksek puan alan farklı mesleklerden bir grup Hollandalı üzerinde yapılan çalışmada, bu ölçekte yüksek puan alan çalışanların işlerinde daha yüksek enerji ve öz yeterliliğe sahip olduklarını göstermiştir (Schaufeli vd. 2001).

Kısacası, meşgul çalışanlar yüksek enerji seviyelerine sahiptir ve çalışmaları konusunda heveslidirler. Üstelik, genellikle çalışmalarına tamamen dalıp giderler ve böylece onlar için işyerinde zaman farkında olmadan akar. Ancak bireylerin iş ortamında, enerjik, adanmış ve işi özümsemiş olması işyerinde çok yoğun çalıştıkları veya çok uzun saatler çalıştıkları anlamına gelmez (Derks vd. 2015: 161).

Kahn (1990) 'a göre, kişisel enerjileri (fiziksel, bilişsel, duygusal ve zihinsel) kendisini iş rolüne adayan kişi ile bu kişinin kendisini ifade etmesine izin veren iş rolü arasında dinamik, diyalektik bir ilişski vardır. Kahn (1992), işe adanma yani angajman kavramını bireyin psikolojik varlığından veya "anda olması" yani tüm varlığı ile bulunduğu anı hissetmesi ve o ana odaklanması deneyiminden ayırmıştır. Başka bir deyişle, burada davranış olarak angajman (kişinin iş rolünü yerine getirirken enerjik olması) psikolojik varlığın, belirli bir zihinsel durumun tezahürü olarak kabul edilir. Buna göre, adanmışlığın (angajman) hem bireysel düzeyde (kişisel gelişim ve gelişim) hem de organizasyonel düzeyde (performans kalitesi) olumlu sonuçlar ürettiği varsayılmaktadır.

İşe adanma ile ilgili diğer tanımlamalara bakıldığında, Maslach ve Leiter'e (1997) göre işe adanmanın, üç alt boyut olan enerji, işe katılım ve işte etkinlik ile karakterize edildiği görülür. Tükenmişlik durumunda, işe adanmanın tersi oluşur yani enerji tükenmeye, sinizm artmaya başlar, etkinlik etkisizliğe dönüşür. Bu yaklaşıma göre işe adanma yani bir diğer deyimle işe angaje olma tükenmişlik sendromu deneyimlenin tersi durumdur. Sonuç olarak, iş sözleşmesi, pozitif, yani tatmin edici ve işin özümsenmesini içeren olumlu, tatmin edici bir zihinsel algı olarak tanımlanır. Buna göre, canlılık ve bağl1lık, tükenmişliğin iki temel belirtisi olan tükenme ve sinizmin doğrudan karşıtı olarak kabul edilir (Bakker vd., 2008: 4).

Önceki çalışmalar, meslektaşların ve öneticilerin sosyal desteğinin, performans geribildiriminin, beceri çeşitliliğinin, özerklik ve öğrenme fırsatları gibi faktörlerin işe adanma ile pozitif ilişkili olduğunu göstermiştir (Bakker ve Demerouti, 2008). Ayrıca çalışanın sorumluğu olduğu göreve ait yüksek iş talepleri olması yani zorlayıcı iş koşullarının olması ve bu koşulları başarıyla sağlayacağına dair inancı olması da işe adanmasına katkıda bulunan bir durumdur (Bakker, Hakanen, Demerouti ve Xanthopoulou, 2007). Bu anlamda, Mauno vd. (2007) ve Xanthopoulou vd.'nin (2007) yaptıkları çalışmada öz yeterlik ve organizasyon temelli öz saygı gibi çeşitli kişisel kaynakların işe adanmayla pozitif anlamda yakinen ilişkili olduğu görülmüştür.

\section{Yenilikçi Örgüt İklimi ve İşe Adanma}

Kuşkusuz bireylerin işe adanabilmeleri için kendilerini psikolojik olarak güvende hissetmeleri çok önemlidir. Bu noktada psikolojik güvenlik çalışırken, işi ile ilgili görevini ifa ederken herhangi bir endişe taşımaması, yaptığı işlerin neticesinde bireysel imajı, statüsü ve kariyeri ile ilgili her hangi bir endişe taşımamasıdır (Kahn, 1990 : 708). Psikolojik olarak kendilerini güvende hisseden bireylerin işlerine adanma ihtimalleri de artmaktadır. Von Krogh vd.2ne (2000) göre de çalışma ortamı atmosferinin güvenli olması ve çalışanlarla ilgilenilebilen bir atmosfer olması, iletişimi, bilgi paylaşımını ve yaratıcı çıktılarını kolaylaştırır. Söz konusu ortam aynı zamanda inovatif örgüt iklimi ile de örtüşen bir ortamdır. İşe adanmışlığı arttıran bireysel kaynaklar (a) hedeflere ulaşmada işlevseldir, (b) tehditlerden ve buna bağli fizyolojik ve psikolojik maliyetlerden korur ve (c) kişisel gelişimi teşvik eder (Xanthopoulou vd., 2008: 236). 
May vd. (2004), bireylerin fiziksel, duygusal ve bilişsel kaynaklara sahip olmalarının, rolleri ile ilgili görevlerini ifa ederken işin zorluklarına ve sıkıntılarına katlanmalarında ve işe kendilerini adamalarında önemli etkenler arasında sayılabileceğini savunur. Yani gerekli kaynaklara ve uygun iş ortamına sahip bireyler işlerini daha büyük bir şevk ve azimle yapabilirler dolayısıyla işe adanma ihtimalleri de daha yüksek olur. Jaiswal ve Dhar'a göre (2015) bir takımın ya da örgütün yenilikçi örgüte sahip olabilmesi için aslında o yapı içerisinde herkesin motive olduğu ve şevkle ulaşmak istedikleri bir vizyonun olması, insanların rahatlıkla fikirlerini söyleyebildikleri ve karar alma mekanizmalarına katılabildikleri bir kültürün olması, çalışanların görev odaklı olmaları, işlerini ciddiye almaları ve mükemmelin peşinde olmaları ve yeniliğin yapı tarafından desteklenmesi gerekir. Aslında söz konusu koşullar altında çalışanların işe adanmaları, yani ilerini benimseyip özümsemeleri ve şevkle yapmaları da daha kolay olacaktır.

Kahn (1990)'a göre işin örgüt üyeleri tarafından anlamlı bulunması, meydan okuyucu, kişiyi geliştirici, alışılmışın dışında yeteneklerin kullanımı ve örgütün geneline katkıda bulunmaya imkan veren firsatların olması işe adanmışlı̆gı arttırır. Söz konusu faktörler aslında inovatif bir örgüt kültürü için de gerekli olan faktörlerdir. Diğer bir yandan, Maslach'1n iddia ettiği gibi (2001) örgüt içerisinde elde edilen ödül ve başarılar da çalışanların işe adanmasında olmasında etkilidir. İnovatif örgütlerde, başarının ödüllendirilmesi ve başarıya götürecek teşebbüslerin teşvik edilmesi ihtimali yüksektir. Dolayısıyla, inovatif bir iklimin yaratacağı kazanç ve kariyer olanakları kuşkusuz çalışanların işlerine daha fazla adanmalarına daha büyük bir heves ve iştiyakla çalışmalarına neden olacaktır.

Pozitif psikoloji bakış açısıyla bakıldığında ise iş hayatında bireylerin sahip oldukları pozitif güçler, pozitif psikolojik sermayedeki gibi bir araya geldiklerinde daha pozitif kaynaklara ve bu kaynakların sağladığı daha pozitif iş sonuçlarına yol açarlar (Frederickson, 2001). Bireyler işleri ve işverenleri ile ilgili pozitif duygulara sahip olduklarında, farklı durumlar ve zorluklar karşısında daha hızlı aksiyon alabilmekte yani aslında ihtiyaç olan cevaplarla ilgili düşünme kapasiteleri artmakta, düşüncelerinin ve reaksiyonlarının kalitesi artmakta ve yelpazesi genişlemektedir (Narcıkara, E.B., 2017: 28). İnovatifliği sağlayan pozitif psikolojik kaynaklar-inovatif örgüt iklimi ve işe adanmışlık arasındaki ilişki de bu denli bir pozitif ilişkidir. Pozitif ve destekleyici bir ortamda çalışanlar inovatif teşebbüslerde de daha rahat bulunabilirler. Olumlu öz değerlendirmelerin, işle ilgili refahın çeşitli yönleriyle yakından ilişkili olduğu gösterilmiştir. Bunun nedeni kişisel kaynaklar ne kadar yüksek olursa, bireylerin öz saygılarının o denli yüksek olmasıdır. Buna karşı1ık, bireylerin belirledikleri hedefler ve yetenekleri arasında yüksek düzeyde uyum yaşamaları muhtemeldir. Bu tür bir hedef kendine uyumu olan bireyler, amaçlarını sürdürmek için doğal olarak motive olurlar ve sonuç olarak memnuniyeti ve işe adanmışlı̆̆ı pozitif anlamda tetiklerler. Bu anlamda, Hakannen vd.'nin (2008) yılında Finlandiya'da diş hekimleri üzerinde yaptıkları araştırmada, bireylerin iş yerinde sahip oldukları psikolojik kaynakların işe adanma üzerinde pozitif etkisi olduğu ve bu pozitif etkinin çalışanların yenilikçileri üzerinde pozitif etki yaptığ görülmüştür. Yine araştırmanın bir sonucu olarak bir spiral şeklinde ilerleyen inovatifliğin yeni psikolojik kaynakların ortaya çıkmasına sebep olduğu ve bu yeni psikolojik kaynakları edinmesinde işe adanma üzerinde pozitif etki yarattığı tespit edilmiş, bireylerin sahip oldukları ve sonradan edindikleri pozitif psikolojik kaynakların aslında helezon etkisi ile inovatifliği etkilediği ve bu inovatifliğin hem işe adanmayı etkilediği hem de işe adanmadan etkilendiği görülmüsstür.

Bir diğer çalışmada Hughes, Awey ve Norman (2008) destekleyici örgüt ikliminin örgütsel bağlılık üzerindeki ilişkisinde işe adanmışlığın ve güvenin aracı etkisini incelemiştir. Araştırmada tüm hipotezler desteklendiği için destekleyici örgüt ikliminin işe adanmışlık üzerindeki pozitif etkisi de desteklenmiş kabul edilmektedir. Yenilikçi örgüt ikliminde de destekleyici bir yönetim tarzı söz konusu olduğu için Hughes, Awey ve Norman'ın (2008) çalışmasındakine benzer bir ilişkinin inovatif örgüt iklimi ile işe adanmışlık arasında da olabileceği düşünülmüştür. Örgütü ve yöneticisini arkasında hisseden çalışan daha özgüvenli ve rahat çalıştığ için risk alabilmekte ve 
daha inovatif davranabilmekte bu durum da işe adanma ihtimallerini arttırabilmektedir. Bu çalışmada ilgili alan yazının bulgularından yola çıkarak yenilikçi örgüt ikliminin çalışanların işe adanmaları üzerinde pozitif etki edeceği öngörülmüş̧ür. Araştırmanın temel hipotezi:

H1: Yenilikçi örgüt iklimi çalışanların işe adanma eğilimlerine pozitif yönde etki eder şeklinde oluşturulmuştur.

\section{Metodoloji}

\section{1. Örneklem ve Veri Toplama Yöntemi}

$\mathrm{Bu}$ çalışmada, araştırma modeline ait saha araştırmasında veri toplama yöntemi olarak kolayda örnekleme yöntemi kullanılmıştır. Araştırmaya ait anket, Linkedin sosyal ağı üzerinden gönderilen linklerle çevrimiçi anketler aracılığı ile toplanmıştır. Araştırmaya, Türkiye'de yerleşik durumda olan kurumsal firmalarda aktif olarak görev yapan ve Linkedin hesabını aktif olarak kullanan beyaz yakalı çalışanlar katılmıştır. Söz konusu anket toplama yönteminin ve örneklemin tercihinde, araştırmanın konusu ile ilintili olarak Linkedin kullanan beyaz yakalı katılımcı olarak tercihinde, söz konusu beyaz yakalı çalışanların İnternet kullanımı ve dolayısıyla teknolojiye ve buna bağlı olarak da yeniliklere karşı daha ilgili olacağı ve ankete katılma konusunda daha istekli olacakları düşünülmüştür.

İlgili saha araştırmasında 1000'i aşkın anket gönderilmesine rağmen 203 kullanılabilir anket elde edilmiştir. Katılımcıların, \%75'i kadın, \% 25'i 20-39 yaş arasında, \% 58'i 30-39 yaş arasında, \% 14'ü ise 40-49 yaş arasındadır. Yani oldukça genç bir katılımcı oranı görülmektedir. Eğitim seviyelerine bakıldığında katılımcıların yüzde 7'si önlisans, \% 41'i lisans, \% 42'si yüksek lisans, ve \% 10’u doktora mezunudur. Dolayısıyla öngörüldüğü gibi eğitim seviyesi yüksek bir katılımc1 gurubu oluşmuştur. Katılımcıların \% 70'i 250 ve üstü çalışan sayısına sahip şirketlerde görev almaktadır. \%74'ü ise hizmet sektöründe çalışmaktadır.

Gözlemlenen değişkenlerin öngörülen boyutlarda yüklenip yüklenmediğini test etmek için açımlayıcı faktör analizi kullanılmıştır. Hipotez testinde SPSS analizleri tercih edilmiştir. Yanıtlarda beşli Likert Ölçeği kullanılmıştır. Çalışmaya ait saha araştırmasında kullanılan ankette, yenilikçi örgüt iklimini ölçmek için Scott and Bruce'un 22 sorudan ve örgüt desteği ve kaynak desteği olmak üzere iki boyuttan oluşan yenilikçi örgüt iklimi ölçeği, işe adanma soruları için ise Schaufeli ve Bakker'in (2002) UWES (Utrecht Work Engagement Scale) İşe adama ölçeğinin 9 soruluk kısa versiyonu kullanılmıştır. İşe adanma soruları canlılık (vigor), işe adanma (dedication) ve özümse (absorption) olmak üzere üç boyuttan oluşmaktadır.

Çalışmada, veriler tanımlayıcı ve çıkarımsal istatistikler açısından ele alınmıştır. Kaiser-MeyerOlkin Örneklemenin Ölçümü Çalışma örneğindeki verilerin yeterli olup olmadığını test etmek için yeterlilik analizi yapılmıştır. Örneklemin yeterlilik katsayısı 0,913, Barlett skoru 0,001'in altında olduğu için, faktör analizi yapılarak devam etmesi anlamlı olarak değerlendirilmiştir.

\subsection{Bulgular}

Faktör analizi neticesinde yenilikçi örgüt iklimi sorularının orijinal ölçekte olduğu gibi iki boyuta ayrıldığı görülmüştür. Ancak her iki boyuttan da bazı soruların çıkarılması gerekmiştir. İşe adanma soruları da orijinal ölçekte olduğu gibi üç boyuta ayrılmıştır, bu ölçekte de özümseme boyutundan bir soru çıkarılmıştır. İlgili faktör yapısı ve Cronbach Alfa değerleri Tablo 1'de gösterilmiştir. 
Tablo 1: Faktör Analizi

\begin{tabular}{|c|c|c|c|c|c|c|}
\hline & & & & & & $\begin{array}{l}\text { Cronbach } \\
\text { Alfa }\end{array}$ \\
\hline & 1 & 2 & 3 & 4 & 5 & \\
\hline CAN1 & 0,924 & & & & & 0.852 \\
\hline$\overline{\text { CAN2 }}$ & 0,86 & & & & & \\
\hline CAN3 & 0,695 & & & & & \\
\hline AD4 & & 0,588 & & & & 0.738 \\
\hline AD5 & & 0,646 & & & & \\
\hline AD6 & & 0,85 & & & & \\
\hline ÖZ8 & & & 0,907 & & & 0.686 \\
\hline ÖZ9 & & & 0,62 & & & \\
\hline YD1 & & & & 0,54 & & 0.907 \\
\hline YD2 & & & & 0,542 & & \\
\hline YD3 & & & & 0,525 & & \\
\hline YD5r & & & & 0,641 & & \\
\hline YD4r & & & & 0,713 & & \\
\hline YD7r & & & & 0,697 & & \\
\hline YD8r & & & & 0,763 & & \\
\hline YD9r & & & & 0,732 & & \\
\hline YD11r & & & & 0,677 & & \\
\hline YD12r & & & & 0,674 & & \\
\hline YD13r & & & & 0,716 & & \\
\hline KD15 & & & & & 0,643 & 0.774 \\
\hline KD16 & & & & & 0,712 & \\
\hline KD20 & & & & & 0,661 & \\
\hline KD21 & & & & & 0,597 & \\
\hline KD22 & & & & & 0,562 & \\
\hline KD19 & & & & & 0,6 & \\
\hline
\end{tabular}

Daha sonra, ilgili faktörlerin birbiriyle ilişkili olup olmadığını anlamak ve çok kutupluluk olup olmadığını incelemek için korelasyon analizi uygulanmıştır. Korelasyon sonuçları Tablo 2'de özetlenmiştir. Tabloda görüldüğ̈̈ gibi, faktörler $(\rho<0.01, \rho<0.05$ seviyesi) arasında anlamlı ilişkiler vardır ve çok-kutupluluk yoktur.

Tablo 2: Korelasyon Analizi

\begin{tabular}{|l|l|l|l|l|l|l|}
\hline & & Canlılık & Adanma & Özümseme & Yenilikçiliğe & Kaynak D. \\
\hline Canlılık & $\begin{array}{l}\text { Pearson } \\
\text { Correlation }\end{array}$ & 1 & & Ö. D. & \\
\hline Adanma & $\begin{array}{l}\text { Pearson } \\
\text { Correlation }\end{array}$ &, $659^{* *}$ & 1 & & & \\
\hline Özümseme & $\begin{array}{l}\text { Pearson } \\
\text { Correlation }\end{array}$ &, $467^{* *}$ &, $592^{* *}$ & 1 & & \\
\hline Yenilikçiliğe Örg. Des. & $\begin{array}{l}\text { Pearson } \\
\text { Correlation }\end{array}$ &, $263^{* *}$ &, $370^{* *}$ &, $193^{* *}$ & 1 & \\
\hline Kaynak Desteği & $\begin{array}{l}\text { Pearson } \\
\text { Correlation }\end{array}$ &, $325^{* *}$ &, $398^{* *}$ &, $185^{* *}$ &, $616^{* *}$ & 1 \\
\hline$* *$ Correlation is significant at the 0.01 level (2-tailed). & & & & \\
\hline
\end{tabular}


Araştırmanın hipotezi test etmek için regresyon analizi uygulanmıştır. Tablo 3'teki regresyon analizi sonuçları incelendiğinde, yenilikçi örgüt ikliminin işe adanma üzerinde pozitif etkisi olduğu görülmüştür. Hipotezlerimizde işe adanmanın her alt boyutu ile yenilikçi örgüt iklimi ayrı ayrı regresyon analizine sokulmuştur. Model 1 yenilikçi örgüt ikliminin işe adanmanın ilk alt boyutu olan canlılık ile arasındaki ilişkiyi incelemektedir. Analiz sonuçları söz konusu ilişkinin istatistiki olarak anlamlı olduğunu göstermektedir (Adjusted R2:,103, Sig:,000), dolayısıyla Hipotez 1 kabul edilmiştir. Model 1'de ayrıca, yenilikçi örgüt ikliminin canlılık üzerindeki ilişkinin yenilikçi örgüt ikliminin kaynak desteği boyutu aracılığı ile gerçekleştiğini göstermiştir. Model 2'de ise yine yenilikçi örgüt ikliminin adanma üzerindeki etkisi incelenmiştir. Analiz sonuçları Model 2'yi destekler niteliktedir (Adjusted R2:,174, Sig:,000). Söz konusu pozitif etki hem yenilik ile ilgili örgütsel destek boyutu hem de kaynak desteği boyutu üzerinden gerçekleşmiştir. Ancak kaynak desteğinin söz konusu pozitif ilişkide etkisi daha büyüktür. Model 3 ise yenilikçi örgüt ikliminin özümseme üzerindeki ilişkiye ait regresyon analizini içermektedir. Analiz sonucunda yenilikçi örgüt ikliminin özümseme üzerindeki pozitif ilişki teyit edilmiş (Adjusted R2:,093, Sig:,034). Ancak bu ilişki yalnızca kaynak desteği boyutunun özümseme üzerindeki ilişkisinden doğan zayıf bir ilişkidir. Regresyon analizi sonuçları, yenilikçi örgüt ikliminin işe adanma üzerindeki ilişkisinin işe adanmanın her üç boyutu için geçerli olmak üzere aslında büyük ölçüde kaynak desteği sayesinde olduğunu göstermiştir. Bu noktada analiz sonuçları bize, insanların kendi görevlerini ifa ederken daha şevk ve gayretle çalışıp işlerine daha fazla adanmalarının, örgütün yenilik yapmaya istekli ve hevesli olmasından ziyade bu istek ve hevesi realize edecek kaynakları çalışanlarına sağlamasından geçtiğini göstermektedir. Örgütün inovatif bir zihniyete sahip olması çalışanlar için önemlidir ama işe adanmaları için bunun bir adım ötesi sayılabilecek durum olan gerekli kaynakların temini büyük önem taşımaktadır. Bu kaynaklar eğitim, zaman, para veya statü olabilir. Tüm bu kaynakların ortak noktası ve kişinin işe adanmasında etkili olan faktör bu kaynağın hem yenilik yapmak için önemli bir etken olması hem de bireysel çıkar sağlamasıdır. Kazan-kazan ilişkisi içerisinde de çalışanların işe adanmaları daha kolay olmaktadır.

Tablo 3: Regresyon Analizi

\begin{tabular}{|c|c|c|c|c|c|c|}
\hline & \multicolumn{2}{|c|}{ Model 1} & \multicolumn{2}{|c|}{ Model 2} & \multicolumn{2}{|c|}{ Model 3} \\
\hline & \multicolumn{2}{|c|}{ Canlılık } & \multicolumn{2}{|c|}{ Adanma } & \multicolumn{2}{|c|}{ Özümseme } \\
\hline & Beta & $\mathbf{t}$ & Beta & $\mathbf{t}$ & Beta & $\mathbf{t}$ \\
\hline CONSTANT & 4,131 & $18,611^{* * * *}$ & 3,224 & $11,395^{* * *}$ & 4,814 & $22,668 * * *$ \\
\hline $\begin{array}{l}\text { Yenilik ile ilgili } \\
\text { Örgütsel Destek }\end{array}$ & 0,088 & 1,142 & 0,252 & $2,553^{*}$ & 0,102 & 1,377 \\
\hline Kaynak Desteği & 0,243 & $3,053 * *$ & 0,318 & $3,139 * *$ & 0,093 & $1,22 *$ \\
\hline $\mathrm{F}$ & 12.015 & & 21.131 & & 4.388 & \\
\hline $\begin{array}{ll}\text { Adjusted } & R \\
\text { Square } & \end{array}$ & 0.103 & & 0.174 & & 0.034 & \\
\hline Sign. & 0.000 & & 0.000 & & 0.014 & \\
\hline
\end{tabular}




\section{Sonuç ve Öneriler}

Yenilikçi örgüt iklimi, yarattığı destekleyici, güvenilir ve motive edici ortamı ile örgütün genelinde değişime ve gelişime açık bir hava yaratır (Khan vd., 2016: 54). Yenilikçi örgüt iklimi, esneklik ve uyum konusuna özellikle hassasiyet gösteren bir örgüt iklimidir (Waheed vd. 2019:4). Bu tarz örgütlerde çalışanların risk alması hem olağan bir durumdur hem de özellikle teşvik edilir. Bu anlamda Chandler, Keller ve Lyon'ın (2000) küçük ve orta ölçekli firmalarda çalışan 429 çalışan üzerinde yaptıkları araştırmada yönetici desteği ve destekleyici ödül sistemlerinin yenilikçi örgüt kültürü oluşumunda büyük etkisi olduğu tespit edilmiştir. Algılanan iş yükü fazlalığının ise yenilikçi örgüt iklimi oluşumuna negatif yönde etki eden bir etmen olduğu tespit edilmiştir. Söz konusu iş ortamı örgütsel adanmışlık açısından da uygun bir iklimdir. Yine aynı çalışmaya göre yenilikçi örgüt kültürüne sahip olan firmalar daha küçük ölçekli daha az formalleşmiş ve örgütlerinin gelişimi için para ve emek harcamaya istekli firmalardır. Formalliğin azalması ve firmaların kültürel anlamda aşırı maliyet odaklı olmamaları çalışanlarında örgütlerinde işe adanmışlıklarını arttırabilecek bir faktördür. İnovatif örgütlerde, inovasyonun gerektirdiği aksiyonları gerçekleştirebilmek için çalışanların potansiyellerini en etkin şekilde kullanabilmeleri ve kendilerini sürekli geliştirmeleri gerektiğini savunur (Khan vd., 2010). İnovatif örgütlerde piyasada rekabet avantajı sağlayabilmek için şirketlerin mutlaka çalışanlarına yatırım yapması onların mesleki gelişimlerine odaklanması gerekir. Kuşkusuz kendilerine yatırım yapılan ve olan potansiyellerinin aktif bir şekilde kullanılmasına müsaade edilen örgütlerde çalışanları işe adanma ihtimalleri de daha yüksek olacaktır.

Kaynakların temini açısından bakıldığında, Baykal'ın (2018) da belirttiği gibi inovatif faaliyetler şirketin belli bir mali gücü olmasını gerektiren ve bu mali gücün önemli bir kısmını gelişim ve araştırmaya harcamasını gerektiren süreçlerdir. Şirketin eğitim, araştırma ve gelişime para harcadığını görmek çalışanların örgüt içindeki rollerine daha sıkı bağlanmalarına ve güvenle örgüt içerisindeki işlerine odaklanmalarına yol açabilmektedir. Dolayısıyla çalışanların gerekli kaynaklarla desteklendiği örgüt iklimlerinde çalışanların işlerini sahiplenmesi ve işlerine adanma ihtimali daha yüksek olmaktadır. Bu anlamda King vd. tarafından 2007 yılında yapılan bir çalışmaya göre yenilikçi örgüt iklimi çalışanların işlerinin gerektirdiği zorlayıcı taleplerin üstesinden gelmelerine sebep olan yardımcı bir güç olarak kabul edilebilir. Çalışanlar inovasyonun desteklendiği bir örgüt ikliminde işlerinin yarattığı baskı ve zorluklarla daha kolay mücadele etmekte, daha az stres yaşamaktadırlar. İnisiyatif almanın yüreklendirildiği yönetici ve örgüt desteğinin söz konusu olduğu bu tarz örgütlerde çalışanlar zor işleri daha kolay halledebilmektedirler ve işlerine daha rahat odaklanıp sahiplenebilirler bu da işe adanma ihtimal ve oranlarını yükseltir.

Bu çalışmada söz konusu yorum ve öngörüler ampirik olarak test edilmek istenmiştir. Her ne kadar literatürde yenilikçi örgüt iklimi ve işe adanma arasındaki ilişkiyi inceleyen ampirik bir çalışma olmasa da yakın kavramlar olan örgütsel inovasyon ve örgütsel bağlılık arasındaki pozitif ilişkiye işaret eden çalışmalar (Henkin and Holliman, 2009; Lambert ve Hogan, 2010) bizi yenilikçi örgüt iklimi ve işe adanma arasındaki ilişkiyi inceleme noktasında cesaretlendirmiştir. Çalışma ilgili alan yazınında yenilikçi örgüt iklimi ve işe adanma arasındaki ilişkiyi inceleyen ilk ampirik araştırma olması açısından yenilikçilik/inovasyon literatürüne önemli bir katkısı olacaktır.

\section{1. Çalışmanın Kısıtları}

Araştırmanın internet üzerinden, Linkedin sosyal ağına üye olan ve bu portalı aktif olarak kullanan beyaz yakalı çalışanlar üzerinde yapılması örneklemin temsil yeteneğini kısmen düşürmüştür. İnternet kullanım oranları düşük kesimlerin, özellikle belli bir yaşın üstündeki çalışanların, araştırmadaki temsilini istenen seviyeye çıkarmak amacıyla bundan sonraki çalışmalarda yüz yüze anket yöntemi ile araştırmaya dahil olan örneklemin temsil gücü kuvvetlendirilebilir. Ayrıca araştırma modeli işe adanmaya yakın kavramlar olan örgütsel bağlılık, işe katılım veya iş tatmini 
gibi örgütsel davranış kavramları ile tekrarlanabilir.

\subsection{Yöneticiler için Tavsiyeler}

$\mathrm{Bu}$ çalışma ile yenilikçi örgüt ikliminin, çalışanların işe adanma eğilimleri üzerinde olumlu bir etkisi olduğu ve bu olumlu etkinin büyük ölçüde yenilikçi örgüt ikliminin kaynak desteği boyutu üzerinden gerçekleştiği görülmüştür. Bu sonuç, çalışanların daha büyük bir şevkle ve adanma ile çalışabilmeleri için, onların nezdinde şirketlerinin gerekli kaynaklara yatırım yapan, yeniliği destekleyen, yenilik aracılığ 1 ile örgütün genelinde ve çalışanların özelinde hayatı kolaylaştırdığına ve gerekli kaynakları sağladığına dair algı yaratması büyük önem taşımaktadır. Araştırma sonuçlarına göre çalışanlar örgütlerinin yeniliğe yatırım yaptığını fark ettiklerinde bu yatırımların kendilerine de bireysel olarak fayda sağlayabileceğini düşündüklerinden ve yeniliğin örgüt üyelerinin hepsinin hayatını daha anlamlı ve avantajlı kılacağını düşündüklerinden işlerine adanmaları daha yüksek olabilmektedir ve ilgili yöneticilerin bu algıyı işe adanmayı sağlamak adına bir araç olarak kullanmalıdır.

\section{KAYNAKÇA}

Agarwal, U. A., Datta, S., Blake-Beard, S., \& Bhargava, S. (2012). Linking LMX, innovative work behaviour and turnover intentions: The mediating role of work engagement. Career development international, 17(3), 208-230.

Amabile, T. M. (2004). Stimulate creativity by fueling passion. In E. A. Locke (Eds.), Handbook of principles of organizational behavior (pp. 331-341). Oxford, UK: Blackwell.

Bakker, A. B., \& Demerouti, E. (2008). Towards a model of work engagement. Career development international, 13(3), 209-223.

Bakker, A. B., Schaufeli, W. B., Leiter, M. P., \& Taris, T. W. (2008). Work engagement: An emerging concept in occupational health psychology. Work \& stress, 22(3), 187-200.

Bakker, A.B., Hakanen, J.J., Demerouti, E. and Xanthopoulou, D. (2007), "Job resources boost work engagement, particularly when job demands are high", Journal of Educational Psychology, Vol. 99, pp. 274-84.

Baykal, E. (2018). Innovativeness in Family Firms: Effects of Positive Leadership Styles. In Strategic Design and Innovative Thinking in Business Operations (pp. 213-232). Springer, Cham.

Berman, E. M., \& Kim, C. (2010). Creativity management in public organizations: Jump- starting innovation. Public Performance \& Management Review, 33, 619-652.

Cai, Z., Liu, H., Huang, Q., \& Liang, L. (2019). Developing organizational agility in product innovation: the roles of IT capability, KM capability, and innovative climate. $R \& D$ Management, 49(4), 421-438.

Chandler, G. N., Keller, C. and Lyon, D. W. (2000). 'Unraveling the determinants and consequences of an innovation-supportive organizational culture', Entrepreneurship Theory and Practice, Vol. 25, No. 1, pp. 59-76.

Chandler, G. N., Keller, C., \& Lyon, D. W. (2000). Unraveling the determinants and consequences of an innovation-supportive organizational culture. Entrepreneurship theory and practice, 25(1), 59-76. 
Chen, C.J., Huang, J.W., and Hsiao, Y.C. (2010) Knowl- edge management and innovativeness: the role of organi- zational climate and structure. International Journal of Manpower, 31, 848870.

Dulaimi, M. F., Nepal, M. P. and Park, M. (2005). 'A hierarchical structural model of assessing innovation and project performance', Construction Management and Economics, Vol. 23, No. 6, pp. 565-577.

Frishammar, J., Kurkkio, M., Abrahamsson, L., \& Lichtenthaler, U. (2012). Antecedents and consequences of firms' process innovation capability: a literature review and a conceptual framework. IEEE Transactions on Engineering Management, 59(4), 519-529.

George, J. M., \& Zhou, J. (2001). When openness to experience and conscientiousness are related to creative behavior: An interactional approach. Journal of Applied Psychology, 86, 513524.

Ghosh, K. (2015). Developing organizational creativity and innovation: toward a model of selfleadership, employee creativity, creativity climate and workplace innovative orientation. Management Research Review, 38(11), 1126-1148.

Hakanen, J. J., Perhoniemi, R., \& Toppinen-Tanner, S. (2008). Positive gain spirals at work: From job resources to work engagement, personal initiative and work-unit innovativeness. Journal of vocational behavior, 73(1), 78-91.

Hammond, M. M., Neff, N. L., Farr, J. L., Schwall, A. R., \& Zhao, X. (2011). Predictors of individual-level innovation at work: A meta-analysis. Psychology of Aesthetics, Creativity, and the Arts, 5, 90-105.

Henkin, A. B., \& Holliman, S. L. (2009). Urban teacher commitment: Exploring associations with organizational conflict, support for innovation, and participation. Urban Education, 44(2), 160-180.

Hsu, M. L., \& Fan, H. L. (2010). Organizational innovation climate and creative outcomes: Exploring the moderating effect of time pressure. Creativity Research Journal, 22(4), 378386.

Hughes, L. W., Avey, J. B., \& Norman, S. M. (2008). A study of supportive climate, trust, engagement and organizational commitment. Journal of Business \& Leadership: Research, Practice, and Teaching (2005-2012), 4(2), 51-59.

Isaksen, S. G., \& Ekvall, G. (2010). Managing for innovation: The two faces of tension in creative climates. Creativity and Innovation Management, 19, 73-88.

Jaiswal, N. K., \& Dhar, R. L. (2015). Transformational leadership, innovation climate, creative selfefficacy and employee creativity: A multilevel study. International Journal of Hospitality Management, 51, 30-41.

Janssen, O., Van de Vliert, E., \& West, M. (2004). The bright and dark sides of individual and group innovation: A special issue introduction. Journal of Organizational Behavior, 25, 129145.

Kahn, W.A. (1990). Psychological conditions of personal engagement and disengagement at work. Academy of Management Journal, 33, 692724.

Khan, M. N., Salman, M., Mufti, U., \& Wajid, M. (2016). Impact of Organizational Justice on Perceived Creative Performance Through Mediating Role of Innovative Climate. Am. J. Bus. Soc, 1, 53-59.

King, E. B., De Chermont, K., West, M., Dawson, J. F., \& Hebl, M. R. (2007). How innovation can alleviate negative consequences of demanding work contexts: The influence of climate for innovation on organizational outcomes. Journal of Occupational and Organizational Psychology, 80(4), 631-645. 
Lambert, E. G., \& Hogan, N. L. (2010). Wanting change: The relationship of perceptions of organizational innovation with correctional staff job stress, job satisfaction, and organizational commitment. Criminal Justice Policy Review, 21(2), 160-184.

Martins, E. C. and Terblanche, F. (2003). 'Building organisational culture that stimulates creativity and innovation', European Journal of Innovation Management, Vol. 6, No. 1, pp. 64-74.

Maslach, C., Schaufeli, W.B. \& Leiter, M.P. (2001). Job burnout. Annual Review of Psychology, $52,397-422$.

Mauno, S., Kinnunen, U. and Ruokolainen, M. (2007), "Job demands and resources as antecedents of work engagement: a longitudinal study", Journal of Organizational Behavior, Vol. 70, pp. 149-71.

May, D.R., gilson, R.L. \& Harter, L.M. (2004). The psychological conditions of meaningfulness, safety and availability and the engagement of the human spirit at work. Journal of Occupational and Organizational Psychology, 77, 11-37.

Menzel, H., Aaltio, I., Ulijn, J. (2007). On the way to creativity: engineers as intrapreneurs in organizations. Technovation 27 (12), 732-743.

Narcıkara, E. B. (2017). Örgüt Ortamında Artarak Yükselen Olumluluk: Pozitif Örgüt Okulu Bakış Perpektifi. İs'te Davranış Dergisi, 2(1), 20-33.

Popa, S., Soto-Acosta, P., \& Martinez-Conesa, I. (2017). Antecedents, moderators, and outcomes of innovation climate and open innovation: An empirical study in SMEs. Technological Forecasting and Social Change, 118, 134-142.

Pot, F. D. (2017). Workplace innovation and wellbeing at work. In Workplace Innovation (pp. 95110). Springer, Cham.

Schaufeli, W. B., \& Bakker, A. B. (2004). Job demands, job resources, and their relationship with burnout and engagement: A multi-sample study. Journal of Organizational Behavior, 25, 293-315. doi:10.1002/job.248

Schaufeli, W.B., Taris, T.W., Le Blanc, P., Peeters, M., Bakker, A.B. and De Jonge, J. (2001), "Maakt arbeid gezond? Op zoek naar de bevlogen werknemer" ("Does work make happy? In search of the engaged worker"), De Psycholoog, Vol. 36, pp. 422-8.

Scott, S. G., \& Bruce, R. A. (1994). Determinants of innovative behavior: A path model of individual innovation in the workplace. Academy of management journal, 37(3), 580-607.

Shalley, C.E., Zhou, J., Oldham, G.R., 2004. The effects of personal and contextual characteristics on creativity: where should we go from here? J. Manag. 30 (6), 933-958.

Shanker, R., Bhanugopan, R., Van der Heijden, B. I., \& Farrell, M. (2017). Organizational climate for innovation and organizational performance: The mediating effect of innovative work behavior. Journal of vocational behavior, 100, 67-77.

Steele, J. and Murray, M. (2004). 'Creating, supporting and sustaining a culture of innovation', Engineering, Construction and Architectural Management, Vol. 11, No. 5, pp. 316-322.

Von Krogh, G.; Ichijo, K.; and Nonaka, I. (2000) Enabling knowledge creation. New York, NY: Oxford University Press, Inc.

Waheed, A., Miao, X., Waheed, S., Ahmad, N., \& Majeed, A. (2019). How New HRM Practices, Organizational Innovation, and Innovative Climate Affect the Innovation Performance in the IT Industry: A Moderated-Mediation Analysis. Sustainability, 11(3), 621.

Xanthopoulou, D., Bakker, A.B., Demerouti, E. and Kantas, A. (n.d.), "The measurement of burnout and engagement: a cross-cultural study comparing Greece and The Netherlands", New Review of Social Psychology (in press). 
Ekonomi, Işsletme ve Maliye Araştırmaları Dergisi, Cilt 1, Sayı 3, 2019, s. 266-279

Zappalà, S., \& Sarchielli, G. (2017). Climate for Innovation, Attitudes to Internet and ICT Adoption in Small Firms. In Impact of e-Commerce on Consumers and Small Firms (pp. 35-50). Routledge. 